
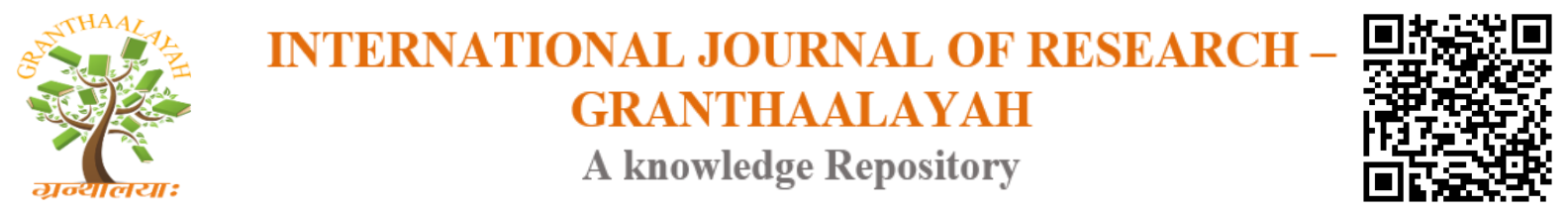

Science

\title{
PREVALENCE OF LATENT TB INFECTION AMONG HEALTH CARE WORKERS, ALJAZEERA STATE TB CENTERS, SUDAN
}

\author{
Juhaina Abdulraiem AL Mosharaf ${ }^{1}$, Dr Adam Abdalla Mater ${ }^{2}$ \\ ${ }^{1}$ Epidemiolgist, Ministry of Health, Kingdom Saudi Arabia \\ ${ }^{2}$ Associate Professor, Alzaiem Alazhari University, Sudan
}

\begin{abstract}
Health care workers $(\mathrm{HCW})$ are at increased risk of latent tuberculosis infection (LTBI) from occupational exposure to Mycobacterium tuberculosis. The objective was to determine the prevalence and risk factors for LTBI among primary HCW in Aljazeera state Sudan. We conducted an analytical study, among $\mathrm{HCW}$ in TB treatment center using a structured questionnaire and an evaluated for LTBI using the tuberculin skin test among $367 \mathrm{HCW}$, the LTBI prevalence was 35.7\% . (64.5\%), We found that the following factors associated with LTBI in $\mathrm{HCW}$ were in age group 30-40 years was $63 \%, 75.2 \%$ of the participants didn't do the skin test for TB, and the high risk among the lab technician represented $41.2 \%$. Our study recommended implementation of sound TB infection control measures in all health care facilities with patients suspected of having infectious.
\end{abstract}

Keywords: TB Infection; Health Care Workers; Patients.

Cite This Article: Juhaina Abdulraiem AL Mosharaf, and Dr Adam Abdalla Mater. (2017). "PREVALENCE OF LATENT TB INFECTION AMONG HEALTH CARE WORKERS, ALJAZEERA STATE TB CENTERS, SUDAN." International Journal of Research - Granthaalayah, 5(12), 465-470. https://doi.org/10.29121/granthaalayah.v5.i12.2017.532.

\section{Introduction}

The worldwide 9.4 million people fell ill with TB in $2013^{(1)}$, Five to $10 \%$ of individuals with latent TB progress to develop overt disease during their life time. The worldwide (40\%) from Health care workers are Infected by latent TB ${ }^{(4)}$, Over $95 \%$ of TB deaths occur in low- and middle-income countries. The Sudan TB is major health problem represent (39\%) from population are positive TB. In Sudan estimated at (28\%) of health care workers contact with TB patients in the hospital but not assess enough of prevalence rate for latent TB infection in health care workers ${ }^{(5)}$. In latent TB infection Persons they are infected with M. tuberculosis and do not feel sick and symptoms, but do not have TB disease. The only sign of TB infection is a positive reaction to the tuberculin skin test or (IGRA) Interferon gamma release assay, persons with latent TB infection are not infectious and cannot spread TB infection to others ${ }^{(8)}$. 
In 2010 it was study conducted for latent TB among Health Care Workers in China they found $45 \%$ they were positive latent TB. ${ }^{(3)}$

The risk of transmission of Mycobacterium tuberculosis from patients to health-care workers (HCWs) is a neglected problem in many low- and middle-income countries (LMICs). Most health-care facilities in these countries lack resources to prevent nosocomial transmission of tuberculosis (TB). ${ }^{(9)}$

There is no data regarding the prevalence rate of latent TB infection among health care workers in Aljazeera State, therefore our study is aimed to found prevalence of latent TB Infection among Health Care Workers in TB centers at Aljazeera state, also to determine risk factor in hospital environment for Health care workers. We expect that our result would be useful to assist planners and decision makers in order to improve safety management in all hospitals in Aljazeera state.

\section{Methodology}

This was TB centers based analytical study conducted in Aljazeera state, Sudan in 2017.

Aljazeera is the second largest city in Sudan at distance about $550 \mathrm{~km}$; it has 45 TB Centers, estimated population of over five million people.

The population study involves all health care workers in TB centers. A representative sample of 367 health care workers were drawn from the study population .

The desired sample size was determined by applying the formula for previous prevalence estimation with the following considerations:-

a) The estimated prevalence of latent TB in Sudan in 2012 was (18\%).

b) Confidence of $(95 \%)$.

c) Error allowed of (4\%).

$$
\mathbf{n}=\frac{\mathrm{K}(\mathbf{P Q} \mathbf{Q})}{\mathbf{E}^{2}}=\frac{(1.96)(0.18 \times 0.82)}{(0.04)^{2}}=367
$$

The main variables collected were:-

*Resident of health care worker.

*Specialty of health staff

*Age

*Sex

*(IGRA) Interferon gamma release assay

*TB test 


\section{Data Collection}

Self-administered questionnaire were distributed together which included information on possible risk factors of socio demographic. In this study, a diagnosis of LTBI was made if the respondent was tested positive by tuberculin skin test, The test was administered by a trained nurse using the Monteux method i.e. $0.1 \mathrm{ml}$ of 2 T.U. of Tuberculin PPD RT 23 SSI was injected intra dermal at the velar aspect of the forearm of respondents. The test was read 48 to 72 hours after application using the palpation method. .Two cut off points for a positive TST (10 and 15 $\mathrm{mm}$ of in duration) were evaluated. The ethical considerations were obtained approval from the department of epidemiology, Alzaiem Alazhari University, and ministry of health.

Also we took permission from everyone who participated in this study prior to collect the needed data; also we followed the standards guide lines for LTB.

\section{Results}

The aim of this study to assess the prevalence of latent TB infection among health care workers in Aljazeera state at TB centers, Sudan 2017.

Our study according to gender was shown $54.5 \%$ males and $45.5 \%$ females. The majority of the participants were university degree holder represented $78.7 \%$.

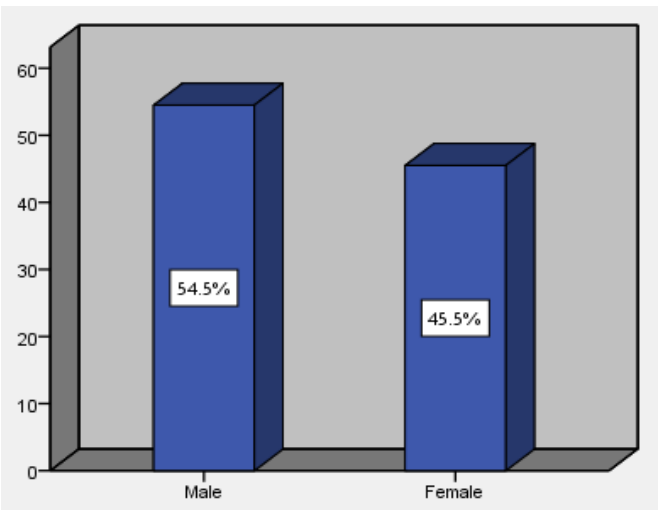

Figure 1: Distribution of participants according to Gender.

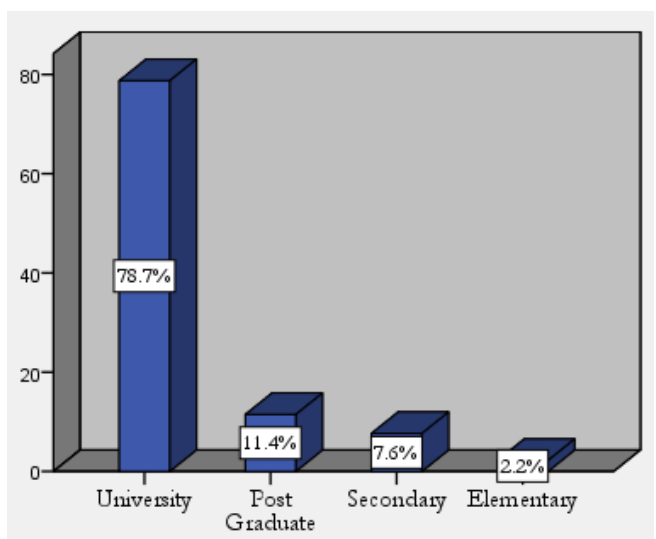

Figure 2: Distribution of participants according to educational level. 


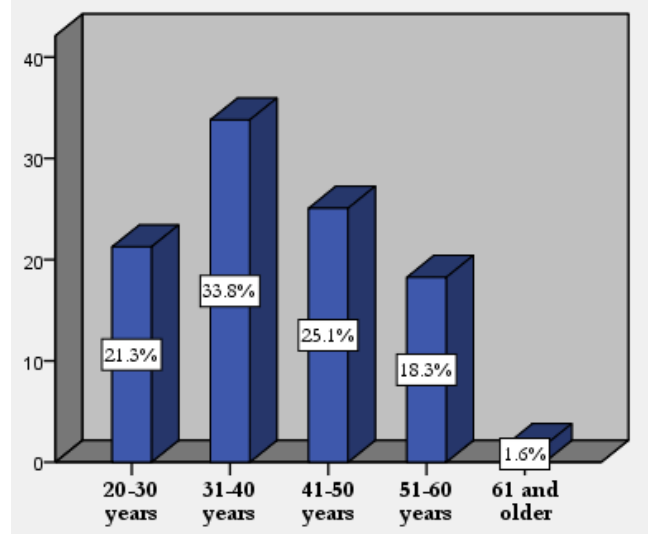

Figure 3: Distribution of participants according to their age.

According to specialization largest categories of participants were physician, nurses equally with $23.7 \%$, next laboratory Specialist with $18.5 \%$. Lastly, radiologist, assistant physician, and other with $12 \%$ or less of the participants.

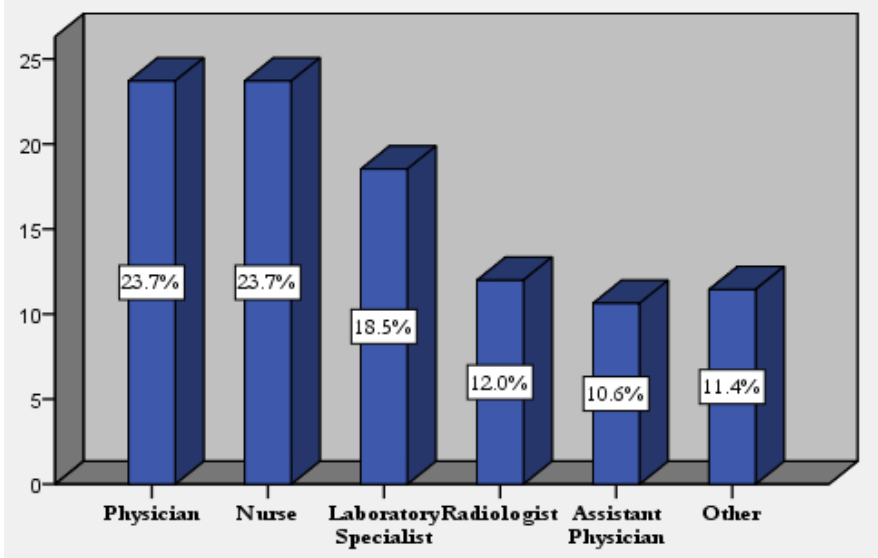

Figure 4: Distribution of participants according to their specialization.

The Prevalence of latent TB among Health Care, of 367 participants of the study sample by using the TST (Tuberculin Skin Test). Out of 367 participants 131 shows positive TST results with percentage of $35.7 \%$, while 236 participants shows negative TST results, in general the prevalence of latent TB infection in our study is $35.7 \%$.

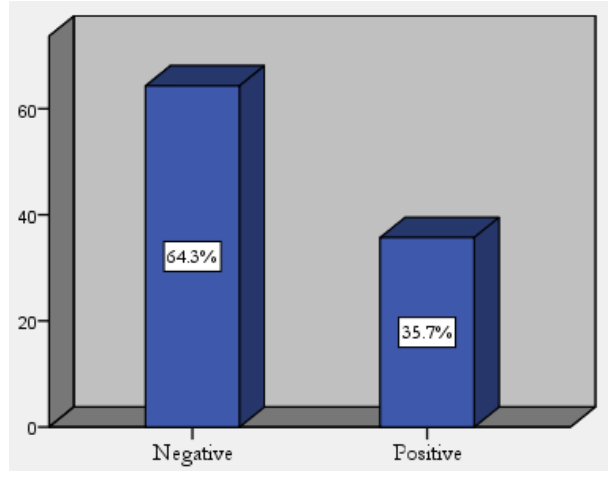

Figure 5: Distribution of participants according LTBI test results. 


\section{Discussion}

Out of 367 participants 131 shows positive TST results with percentage $35.7 \%$, while 236 participants shows negative TST results, it is accepted result if we compared it with the study by Joshi 54\% prevalence rate of LTBI from 263 participant, among HCWs. Also agreed with other study by Krishna $265 \mathrm{HCW}$ were , 177 (67\%) had a positive TST and 159 (60\%) negative, Prevalence and risk factors of latent tuberculosis infection among health care workers in Malaysia(23)

In our study Compared the odds for different specializations shows higher percentage (28\%) among laboratory specialist, followed by assistant physician, and physician than the other specializations, which agreed with study by Zhang X1 the highest prevalence was found among laboratory staff $(43.4 \%)$ in the different workplaces.

In this study we found the high rate it was $(33 \%)$ between age 25 and 29 years old related with occupational factors including job category, workplace and risk group were significantly associated with LTBI it agree with MORAA her result (45\%) between age 25 and 29 years old.

Tuberculosis continues to be an important disease both in humans and animals as it causes mortality and economic losses worldwide, it correct if we comber with our study with our result (89\%) almost of HCW are low income the social economic impact of LTB.

Our study concluded that the prevalence of latent tuberculosis infection in Aljazeera state, Sudan was relatively high TB burden in Sudan. So we recommended the health authorities in Aljazeera State to implement the sound control measures regarding LTBI.

\section{References}

[1] https://www.ncbi.nlm.nih.gov/pubmed/16088473

[2] https://www.cdc.gov/tb/publications/factsheets/general/ltbiandactivetb.htm

[3] Http://Www.Cdc.Gov/Tb/Publications/Factseries/Prevention_Eng.

[4] http://Medical-Dictionary.The free dictionary.Com/Tuberculosis

[5] https://www.encyclopedia.com/medicine/diseasesandconditions/pathology/tuberculosis

[6] Zwerling, A., van den Hof, S., Scholten, J., Cobelens, F., Menzies, D., \&Pai, M. Interferongamma release assays for tuberculosis screening of healthcare workers: a systematic review. Thorax, 67(1), 62-70(2012).

[7] Cohn, D. L., O’Brien, R. J., Geiter, L. J., Gordin, F., Hershfield, E., \&Horsburgh, C.. Targeted tuberculin testing and treatment of latent tuberculosis infection. MMWR Morb Mortal Wkly Rep, 49(6), 1-54(2000)

[8] http://apps.who.int/medicinedocs/documents/s23113en/s23113en.pdf

[9] https://www.cdc.gov/features/diseasesconditions.html

[10] https://en.wikipedia.org/wiki/Tuberculosis

[11] https://www.cdc.gov/tb/education/corecurr/pdf/chapter3.pdf

[12] https://www.ninds.nih.gov

[13] http://www.lancasterisd.org

[14] https://www.cdc.gov/tb/publications/faqs/pdfs/qa.pdf

[15] https://blog.pkids.org/category/tb/ 
[16] Mok, J. H.. Diagnosis and treatment of latent tuberculosis infection in healthcare workers. Tuberculosis and respiratory diseases, 79(3), 127-133(2016)

[17] Driver, C. R., Stricof, R. L., Granville, K., Munsiff, S. S., Savranskaya, G., Kearns, C., \&Oxtoby, M.. Tuberculosis in health care workers during declining tuberculosis incidence in New York State. American journal of infection control, 33(9), 519-526(2005).

[18] Dutta, N. K., \&Karakousis, P. C.. Latent tuberculosis infection: myths, models, and molecular mechanisms. Microbiology and Molecular Biology Reviews, 78(3), 343-371(2014)

[19] https://emedicine.medscape.com/article/230802-workup

[20] Padmapriyadarsini, C., Narendran, G., \&Swaminathan, S.. Diagnosis \& treatment of tuberculosis in HIV co-infected patients. The Indian journal of medical research, 134(6), 850(2011)

[21] http://misc.medscape.com

[22] Joshi, R., Reingold, A. L., Menzies, D., \&Pai, M. Tuberculosis among health-care workers in low-and middle-income countries: a systematic review. PLoS medicine, 3(12), e494. (2006)

[23] Mirtskhulava, V., Kempker, R., Shields, K. L., Leonard, M. K., Tsertsvadze, T., del Rio, C., \& Blumberg, H. M.. Prevalence and risk factors for latent tuberculosis infection among health care workers in Georgia. The International Journal of Tuberculosis and Lung Disease, 12(5), 513-519. (2008)

*Corresponding author.

E-mail address: juhina16@ hotmail.com 